\title{
A Parallel Prospective Open Label Comparative study between the Characteristics of Unilateral Spinal and Paravertebral Blockade in Patients Undergoing Inguinal herniorrhaphy
}

\author{
Authors \\ Dr Purbasha Roy MBBS, MD ${ }^{1}$, Dr Amartya Das MBBS, MD, DNB, IDRA ${ }^{2 *}$ \\ ${ }^{1}$ Senior Resident of Anaesthesiology, Panskura Superspeciality Hospital, Midnapore (East) \\ ${ }^{2}$ Junior Consultant, Dept of Anaesthesiology, ILS Hospitals, Dum Dum \\ *Corresponding author \\ Dr Amartya Das MBBS, MD, DNB, IDRA
}

\begin{abstract}
Introduction: Inguinal hernia repair can be performed under satisfactory anaesthetic conditions using general, regional and peripheral nerve block anaesthesia. The paravertebral block, being segmental in nature, provides some advantages regarding haemodynamic stability, early ambulation and prolonged duration of analgesia and may be a viable alternative to unilateral spinal anaesthesia.

Methods: Seventy consenting male patients aged between 18-65 years, of ASA Grade I \& II status, undergoing elective unilateral inguinal hernia repair were randomised into two groups, 35 patients each to receive either the four segment (T10-L1) paravertebral block (Group P) or unilateral spinal anaesthesia (Group S) respectively. There after intra-operative and post-operative parameters were recorded and compared between these two groups using standardized statistical methods.

Results: Patients in Group P had lesser rescue analgesic requirement, longer duration of sensory block, no motor block leading to early ambulation, better haemodynamic stability, lesser side effects than patients in Group S. However the block performance time and time to onset of anaesthesia was significantly higher in Group P.

Conclusion: Paravertebral block is advantageous in respect to post operative analgesia and early ambulation compared to unilateral spinal anaesthesia.
\end{abstract}

\section{Introduction}

Inguinal hernia repair is one of the most commonly performed surgeries worldwide ${ }^{1}$. A wide variety of anaesthetic techniques have been used for inguinal hernia repair such as local anaesthesia, spinal/epidural anaesthesia in conjunction with intravenous sedation and general anaesthesia ${ }^{2}$. Yet, there is no consensus about the optimum mode of anaesthesia.

Inguinal herniorraphy is not a quick operation, and, there may be possibility of prolonged recovery, if the patient is given general anaesthesia $^{3}$. Local anaesthesia by infiltration is often uncomfortable for hernia patient ${ }^{4}$, a large 
dose of anaesthetic drug may be required, and this technique is often supplemented with heavy premedication or sedation, using drugs with slow elimination $^{3}$. Advantages of regional anaesthesia are, absence of unconsciousness, absence of respiratory depression, lower rates of post operative nausea and vomiting and more rapid recovery $^{5,6}$.

In spinal anaesthesia (SA) drug is administered in subarachnoid space which causes sympathetic block and thus may lead to specific cardiovascular complications. But it suppresses stress response to surgical intervention which is beneficial ${ }^{7}$.

Paravertebral block(PVB) produces ipsilateral segmental analgesia through injection of local anaesthetics onto the spinal nerve roots alongside the vertebral column ${ }^{8}$. The unilateral administration of local anaesthetic in the nerve roots without involving central nervous system, avoids the adverse effects of SA.

\section{Methodology}

After obtaining ethics committee clearance, 70 patients of ASA Physical Status I \& II,scheduled for elective inguinal hernia surgery, were randomized following a sealed envelope method to receive either paravertebral block (Group P) or unilateral spinal anaesthesia (Group $S)$. All patients were given oral alprazolam $0.5 \mathrm{mg}$ on night before surgery. Eight hours fasting was ensured \& patients were premedicated with oral ranitidine $150 \mathrm{mg}$ two hours before surgery. After entering the operating room standard monitors (ECG, NIBP, SpO2) were attached and baseline parameters were recorded. Patients were cannulated with $18 \mathrm{G}$ intravenous cannula and ringer lactate infusion $(10 \mathrm{ml} / \mathrm{kg})$ was started. All the necessary equipments for general anaesthesia and resuscitation were kept ready in case of block failure or any complication. Supplemental O2 were given @ 2lits/min through nasal prong during placement of the block and surgery. All the patients were sedated with iv midazolam $2 \mathrm{mg}$ and fentanyl 50 microgram to avoid anxiety \& discomfort during the procedure.

A senior resident under the direction of a consultant anaesthesiologist performed the blocks. With all aseptic precautions, SA was performed in lateral position (operative side dependent) with 26G Quincke needle using midline approach at L2-L3 or L3-L4 intervertebral space. Subarachnoid injection was given with $15 \mathrm{mg}$ bupivacaine heavy $0.5 \%$. Patient was kept in the same lateral position for further 10mins and then turned supine for surgery.

In Group P patients, the PVB was given in sitting position. The spinous processes of vertebral bodies between T10 and L1 were identified and a mark was placed at $3 \mathrm{~cm}$ lateral to each spinous process on the operative side. Under sterile conditions, $1 \mathrm{ml}$ of $2 \%$ lignocaine was injected subcutaneously on the marked area with a $26 \mathrm{G}$ needle. A $22 \mathrm{G}, 10 \mathrm{~cm}$ insulated needle (Stimuplex-A B-Braun Germany) connected to a nerve stimulator (Stimuplex NHS12, B-Braun Germany) was inserted perpendicular to the skin and the transverse process of vertebra was contacted at $4-5 \mathrm{~cm}$ depth. Initial setting of nerve stimulator was $1.5 \mathrm{~mA}$ current, $100 \mathrm{~ms}$ pulse width and $2 \mathrm{~Hz}$ frequency. The needle was withdrawn and redirected caudally below the transverse process not more than $1-1.5 \mathrm{~cm}$ deeper than initial insertion and motor stimulation of abdominal rectus muscle was noticed. Muscle contraction was associated with sensory stimulation or paresthesia in the respective area. The needle was repositioned till the best stimulation is achieved with minimal current strength, e.g. 0.5-0.6 mA. The position was further confirmed correct if $1 \mathrm{ml}$ of $2 \%$ lignocaine abolished the sensory and motor stimulation. After that, $5 \mathrm{ml}$ of inj. bupivacaine $0.5 \%$ was injected at each vertebral level with repeated aspirations to avoid accidental vascular injection. Then the patient was turned supine for surgery. 


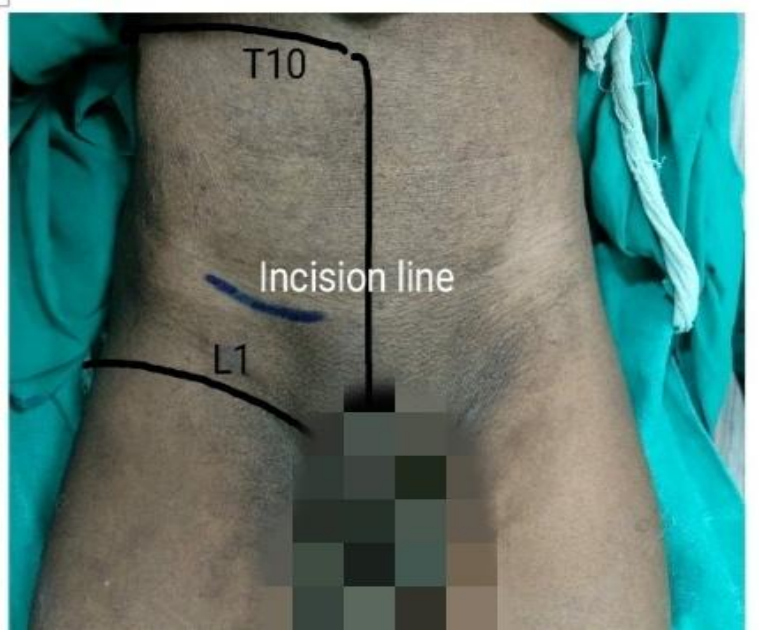

Pic 1: Dermatomal distribution

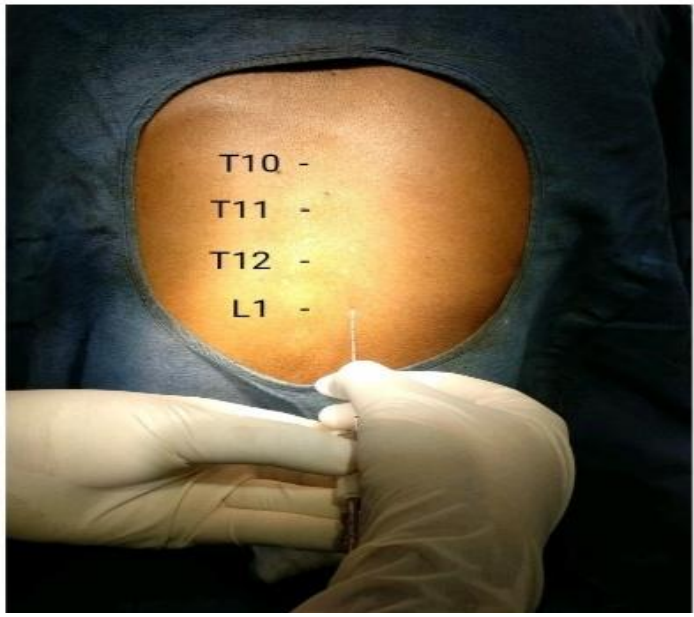

Pic 2: PVB procedure
In both the groups, time to block performance, block characteristics i.e. time to onset of sensory block, peak level of sensory block were recorded. Onset of sensory block was assessed by pin prick discrimination on the operative side at every5mins interval upto30mins. The block was considered successful if loss of pin prick discrimination started within $15 \mathrm{mins}$ or if sensory block (T10L1) is achieved within 30mins. Otherwise it was considered as block failure and the patient was excluded from the study.

Heart rate, NIBP, ECG, SpO2 were monitored at 2.5 mins interval for 115 mins, then at $15 \mathrm{mins}$ interval till the end of the surgery and postoperatively at 2,4,6,12 and $24 \mathrm{hrs}$. Any episode of hypotension (MAP less than $20 \%$ of baseline value) was treated with iv fluid and if needed with $6 \mathrm{mg}$ bolus of mephentermine. Bradycardia ( $\mathrm{HR}<60 \mathrm{beats} / \mathrm{min})$ was managed with iv atropine $0.6 \mathrm{mg}$ if required.

In PACU, the patients were evaluated using Modified Aldrete Scoring system wherein if score is $>9$, patients bypassed the PACU directly to ward. The patients were observed postoperatively upto $24 \mathrm{hrs}$ and the duration of post operative analgesia was recorded by noting the time to $1 \mathrm{st}$ post- operative rescue analgesic administration from placement of the block. Additionally the following parameters were also recorded: total analgesic consumption in 1 st 24 hours postoperatively, time to recovery from sensory \& motor block (modified Bromage score), time to ambulation, Visual analog score and incidence of side effects (PONV, shivering, urinary retention, bloody puncture, local anaesthetic systemic toxicity and pneumothorax). Visual analogue score $>4$ were treated with infusion paracetamol (1g) and PONV were treated with $4 \mathrm{mg}$ iv ondansetron. Patients who were unable to pass urine despite bladder fullness within six postoperative hours, or complained of urinary retention were catheterised with simple rubber catheter, maintaining strict asepsis.

\section{Sample Size Calculation and Statistical Analysis}

Sample size for the study was calculated on the basis of time to administration of $1^{\text {st }}$ rescue analgesic as a primary outcome. It was estimated that 35 subjects would be required per group in order to detect a difference of $30 \mathrm{mins}$ in this parameter with $80 \%$ power and $5 \%$ probability of type I error. This calculation assumes standard deviation of the time parameter to be $45 \mathrm{mins} \&$ two-sided testing. Sample size calculation was done by Master 2.0 (Department of Biostatistics, Christian Medical College-Vellore).

Data was summarised by appropriate descriptive statistics, namely mean or median as a measure of central tendency dependent on the distribution of data \& standard deviation or inter-quartile range as measure of dispersion. Counts and percentages were used to summarise categorical data. Numerical variables were compared between 
groups by Students unpaired t-test if normally distributed or Mann-Whitney U-test if skewed. Chi- square test or Fisher's exact test were employed to compare categorical variables between groups. All analysis were two-tailed and $\mathrm{p}<0.05$ was taken as statistically significant.

\section{Result \& Analysis}

No patients were excluded from study as there was no incidence of block failure needing conversation to general anaesthesia.

\section{Demographic profile and ASA grade}

The demographic profile of the patients of both groups were comparable with regards to age, height, weight and ASA grade.

Table 1: Demographic profile and ASA grade

\begin{tabular}{|l|c|c|c|}
\hline $\begin{array}{l}\text { Demographic and } \\
\text { other parameters }\end{array}$ & $\begin{array}{c}\text { Group P } \\
\text { Mean } \pm \text { SD }\end{array}$ & $\begin{array}{c}\text { Group S } \\
\text { Mean } \pm \text { SD }\end{array}$ & P value \\
\hline Age(years) & $45.49 \pm 12.251$ & $45.74 \pm 12.930$ & 0.932 \\
\hline Height(cm) & $165.99 \pm 5.762$ & $166.44 \pm 3.829$ & 0.697 \\
\hline Weight(Kg) & $73.33 \pm 8.076$ & $71.31 \pm 6.118$ & 0.244 \\
\hline ASA PS (I/II) & $20 / 15$ & $21 / 14$ & 1.000 \\
\hline
\end{tabular}

\section{Block Characteristics}

- Time taken to perform the block was significantly lower in group $\mathrm{S}$.

- Time to loss of pin prick sensation and time to reach $\mathrm{T} 10$ dermatome were significantly earlier in group $\mathrm{S}$.
- Time to recovery from sensory block was significantly earlier in group $\mathrm{S}$, whereas time to recovery from motor block and time to ambulation were significantly less in group $\mathrm{P}$.

Table 2: Block characteristics

\begin{tabular}{|c|c|c|c|}
\hline Block characteristics & $\begin{array}{c}\text { Group P } \\
\text { Mean } \pm \text { SD }\end{array}$ & $\begin{array}{c}\text { Group S } \\
\text { Mean } \pm \text { SD }\end{array}$ & $P$ value \\
\hline Time_block performance (Mins) & $9.66 \pm 1.765$ & $3.40 \pm 0.497$ & 0.000 \\
\hline Time_loss of pin prick sensation (Mins) & $4.06 \pm 1.11$ & $1.83 \pm 0.382$ & 0.000 \\
\hline Time_T10 dermatome (Mins) & $4.06 \pm 1.11$ & $3.46 \pm 0.505$ & 0.031 \\
\hline Time_sensory recovery (Hrs) & $7.02 \pm 0.550$ & $2.66 \pm 0.423$ & 0.000 \\
\hline Time_motor recovery (Hrs) & 0 & $2.23 \pm 0.279$ & 0.000 \\
\hline Time_ambulation (Hrs) & $2.86 \pm 0.284$ & $5.66 \pm 0.355$ & 0.000 \\
\hline
\end{tabular}

Figure 1: Comparison of block characteristics

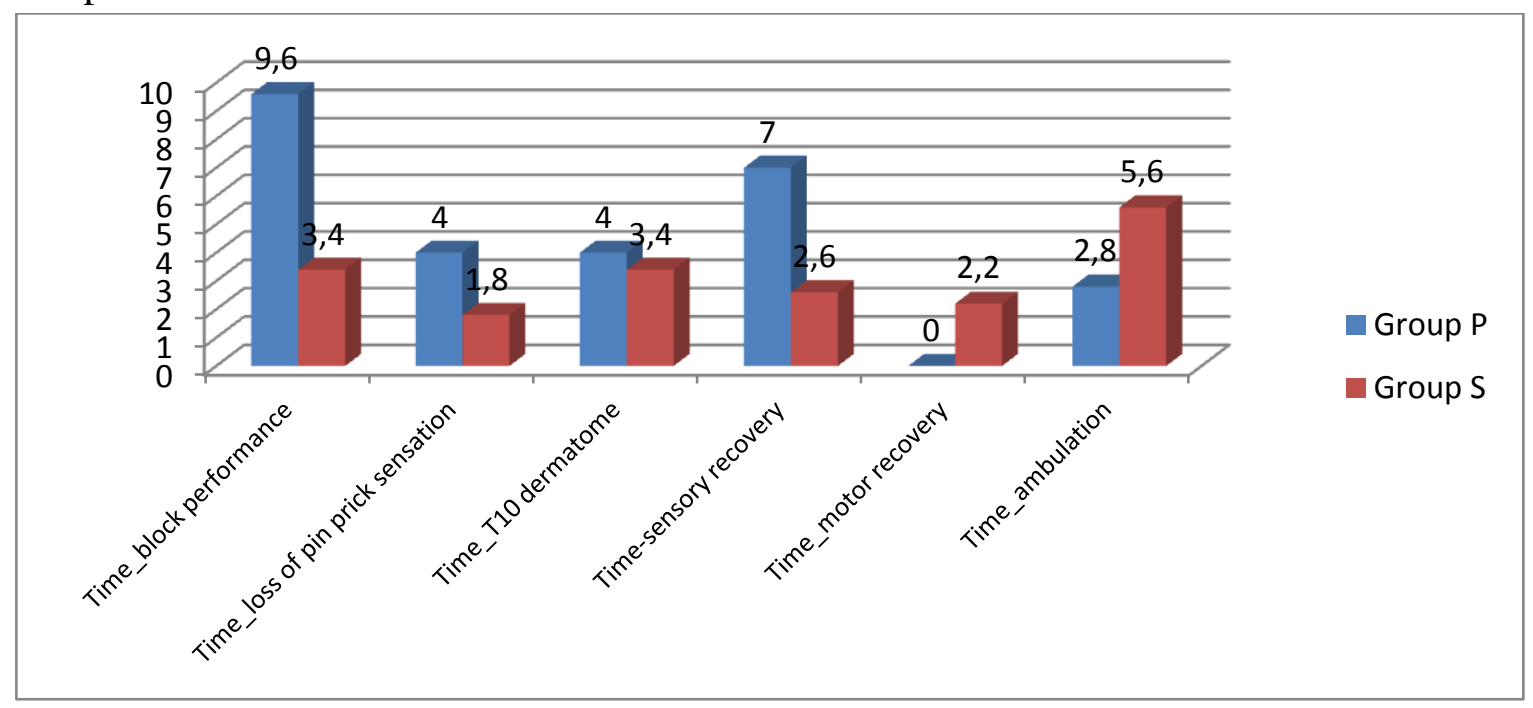

- Peak level of sensory block was significantly higher in Group S than in Group P. 


\section{JMSCR Vol||08||Issue ||07||Page 536-547||July}

Figure 2: Comparison of peak level of sensory block

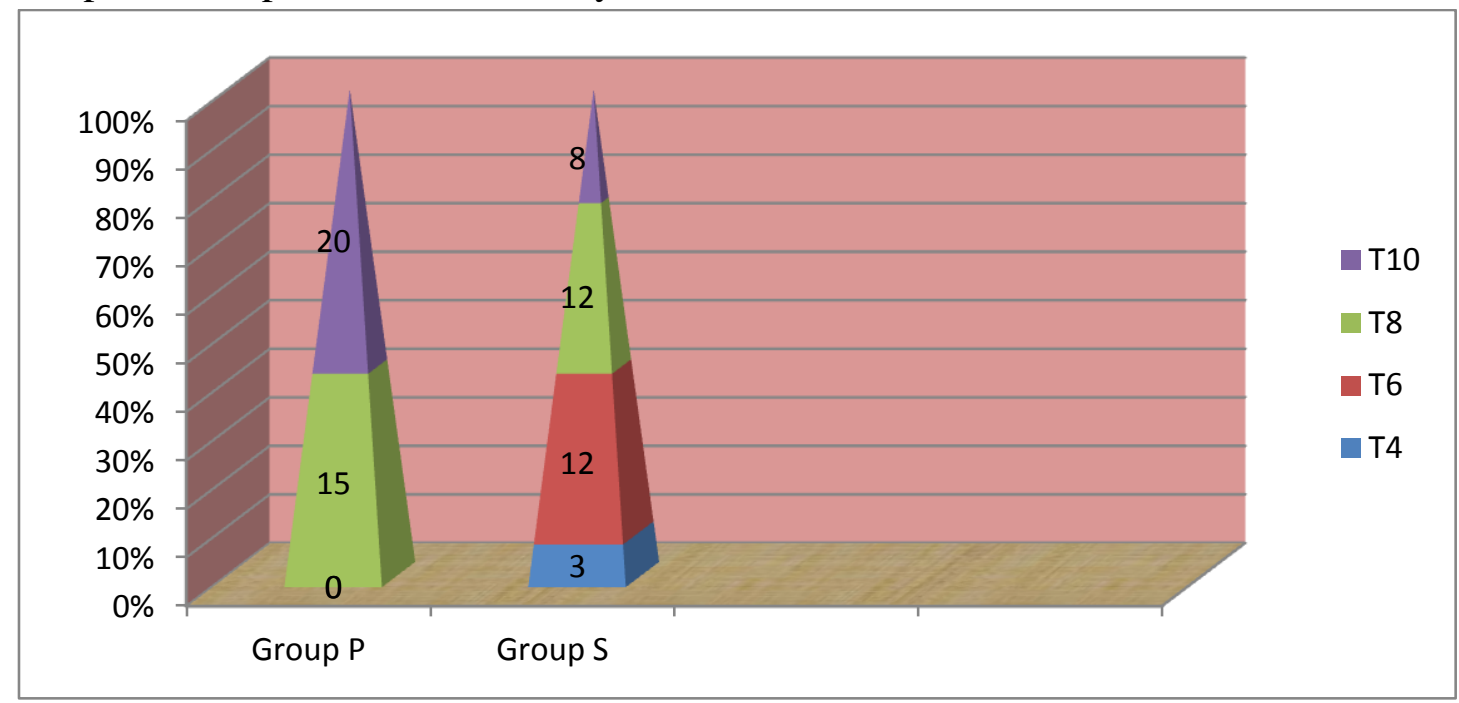

\section{Analgesic characteristics}

- Duration of analgesia which was assessed by time to administration of $1^{\text {st }}$ rescue analgesic was prolonged in Group $\mathrm{P}$ in comparison to Group S.
- Total rescue analgesic requirement in $24 \mathrm{hrs}$ was significantly higher in Group S.

Figure 3: Time of administration of $1^{\text {st }}$ rescue analgesic

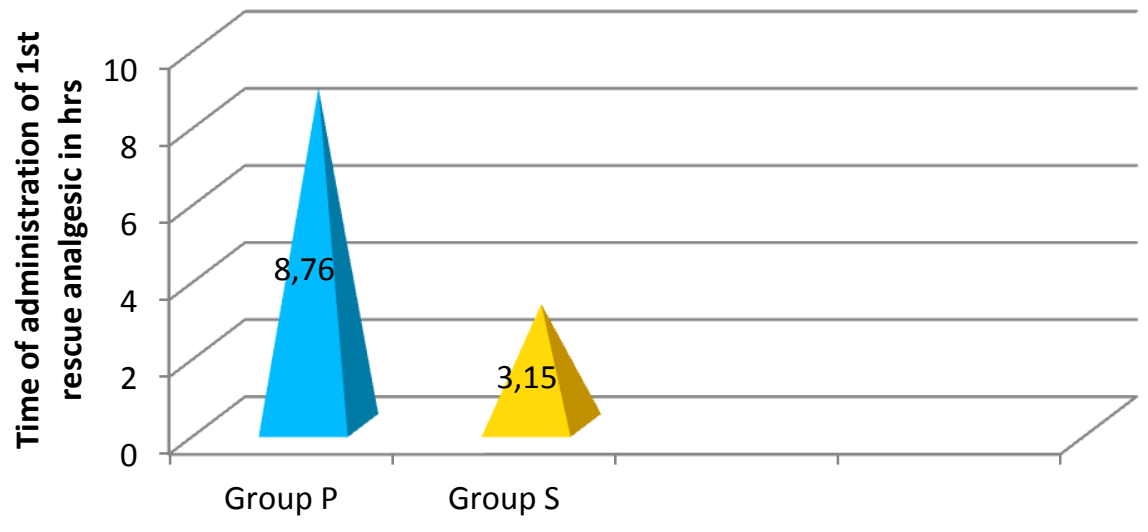

Figure 4: Total rescue analgesic required in $24 \mathrm{hrs}$

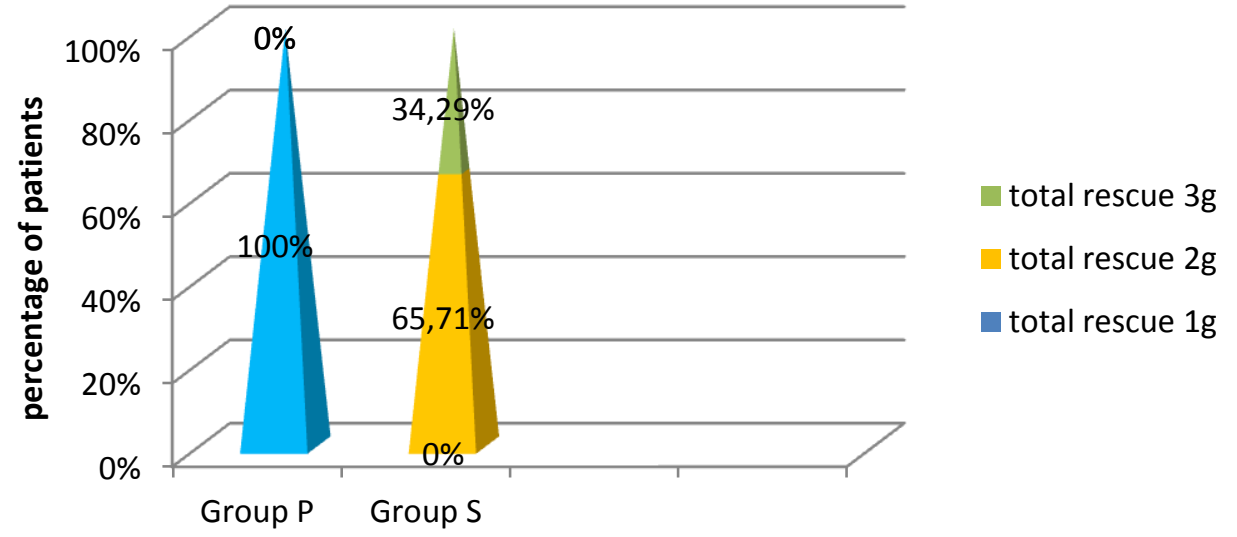




\section{JMSCR Vol||08||Issue ||07||Page 536-547||July}

\section{Hemodynamic Parameters}

Figure 5: Trend of Heart Rate

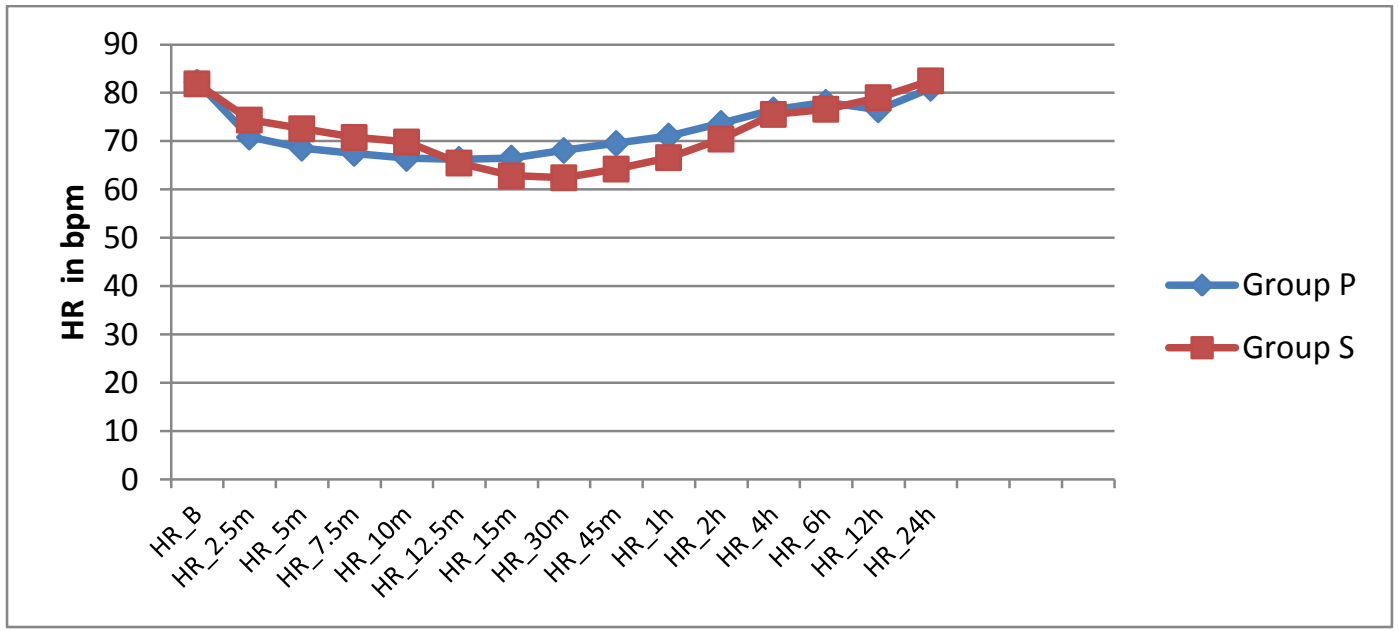

Applying the Student's unpaired $\mathrm{T}$ test it was found that there was statistically significant decrease in HR in Group S for the duration from $15 \mathrm{mins}$ to $2 \mathrm{hrs}$ after block performance.

Figure 6: Trend of SBP

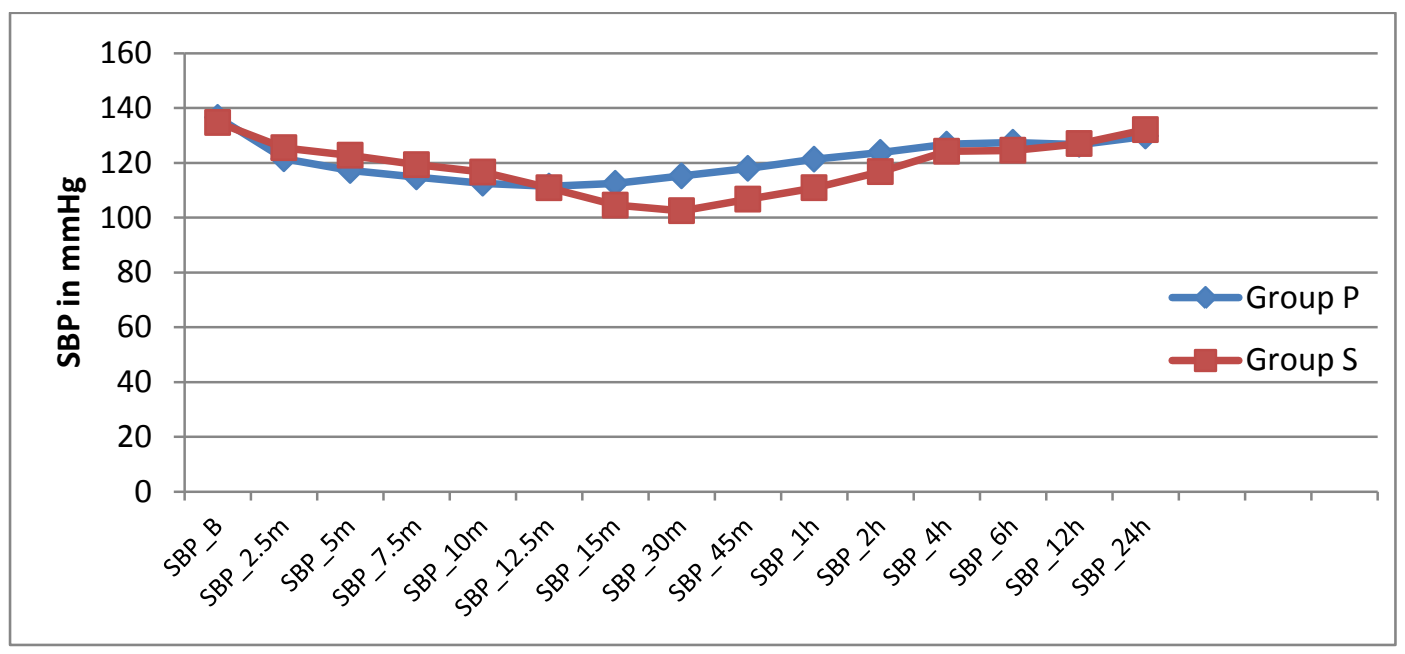

Figure 7: Trend of MAP

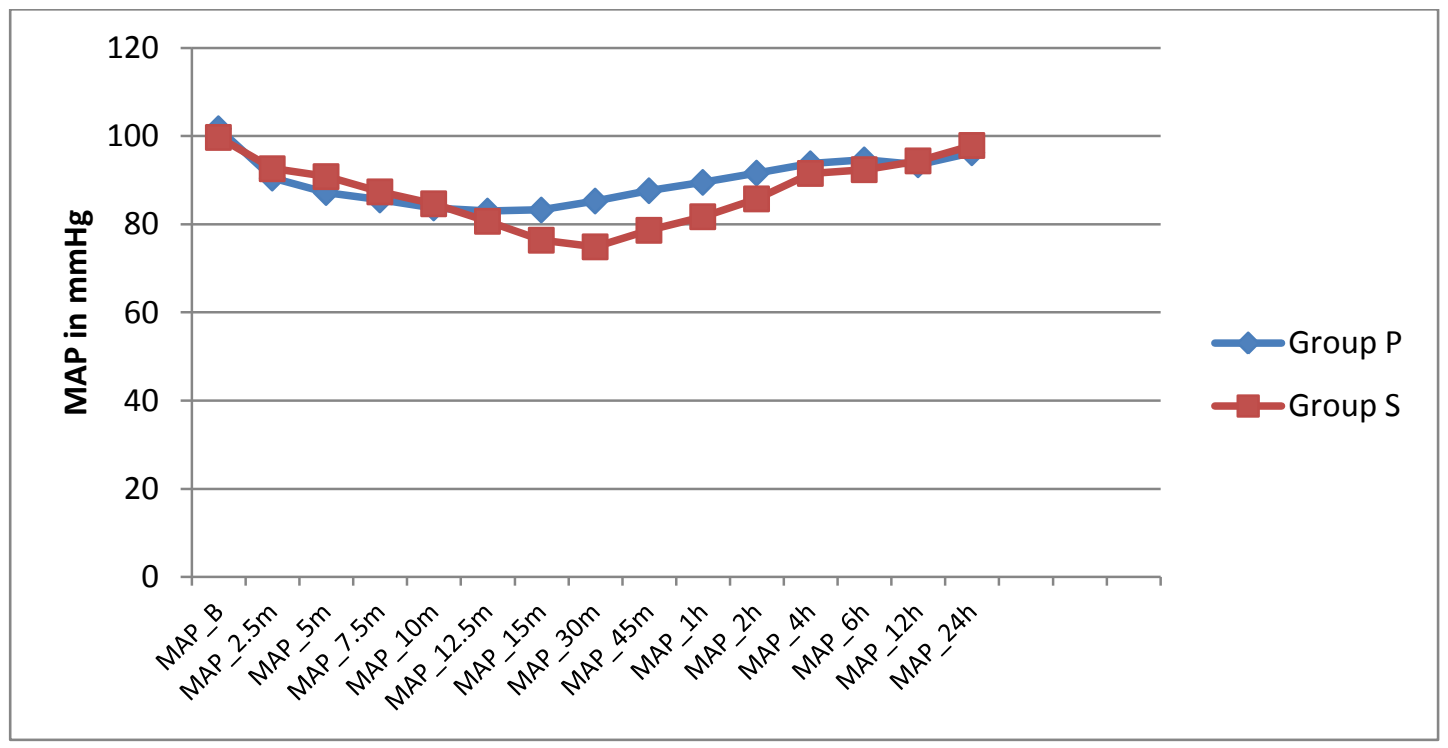




\section{JMSCR Vol||08||Issue ||07||Page 536-547||July}

Figure 8: Trend of DBP

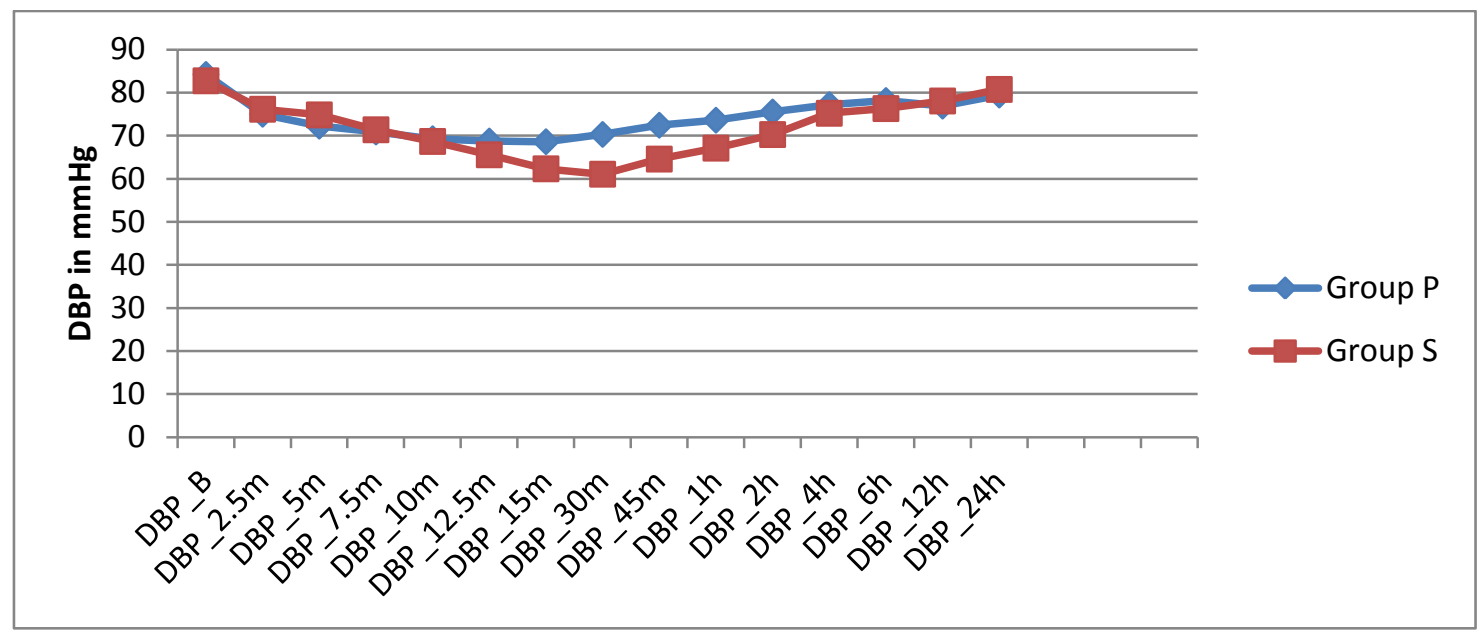

Applying the Student's unpaired $\mathrm{T}$ test it was found that there was statistically significant difference in SBP, MAP \& DBP between the groups. At 5mins patients of group $\mathrm{P}$ showed significant decrease in SBP, MAP whereas between $15 \mathrm{mins}-2 \mathrm{hrs}$ the patients of group $\mathrm{S}$ showed significant decrease in SBP and
MAP.DBP was significantly decreased in group $\mathrm{S}$ between 12.5 mins to $2 \mathrm{hrs}$.

\section{Modified Bromage Score (MBS)}

There was statistically significant increase in MBS in groups $\mathrm{P}$ for the duration from $2 \mathrm{~h}$ to $4 \mathrm{~h}$ in comparison to the patients of group $\mathrm{S}$.

Figure 9: Trend of MBS

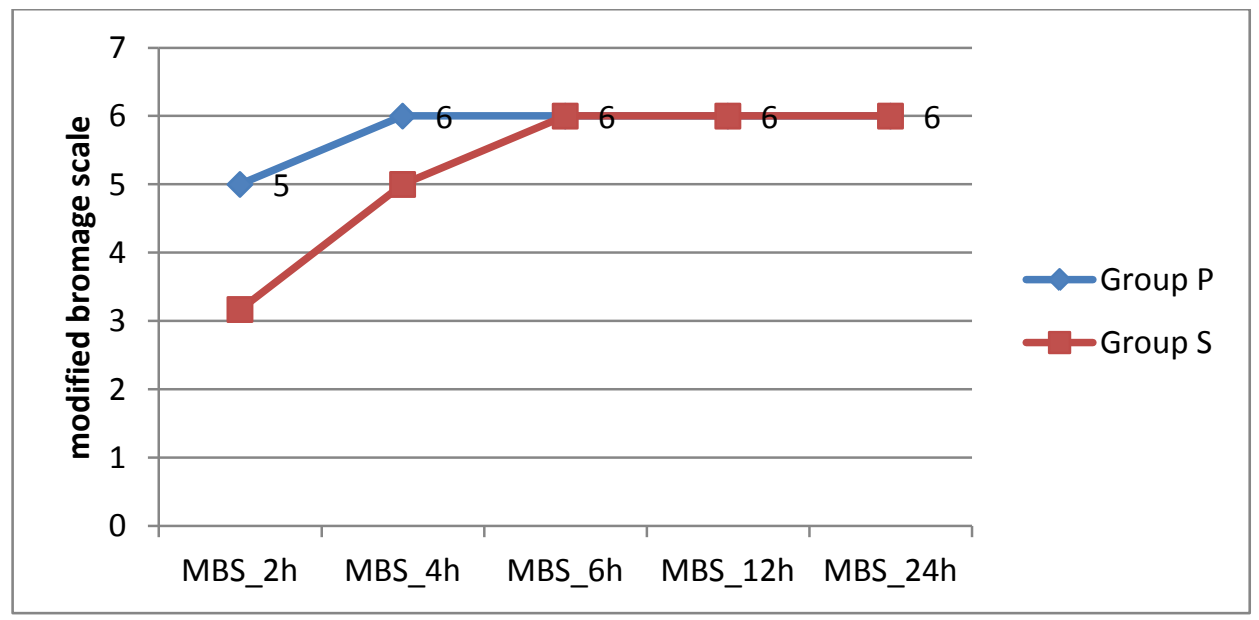

\section{VAS score}

The patients of group $S$ showed statistically significant increase in VAS score in comparison to the patients of group $\mathrm{P}$ during the time period of $2 h-4 h \& 12 h$. 


\section{JMSCR Vol||08||Issue ||07||Page 536-547||July}

Figure 10: Trend of VAS score

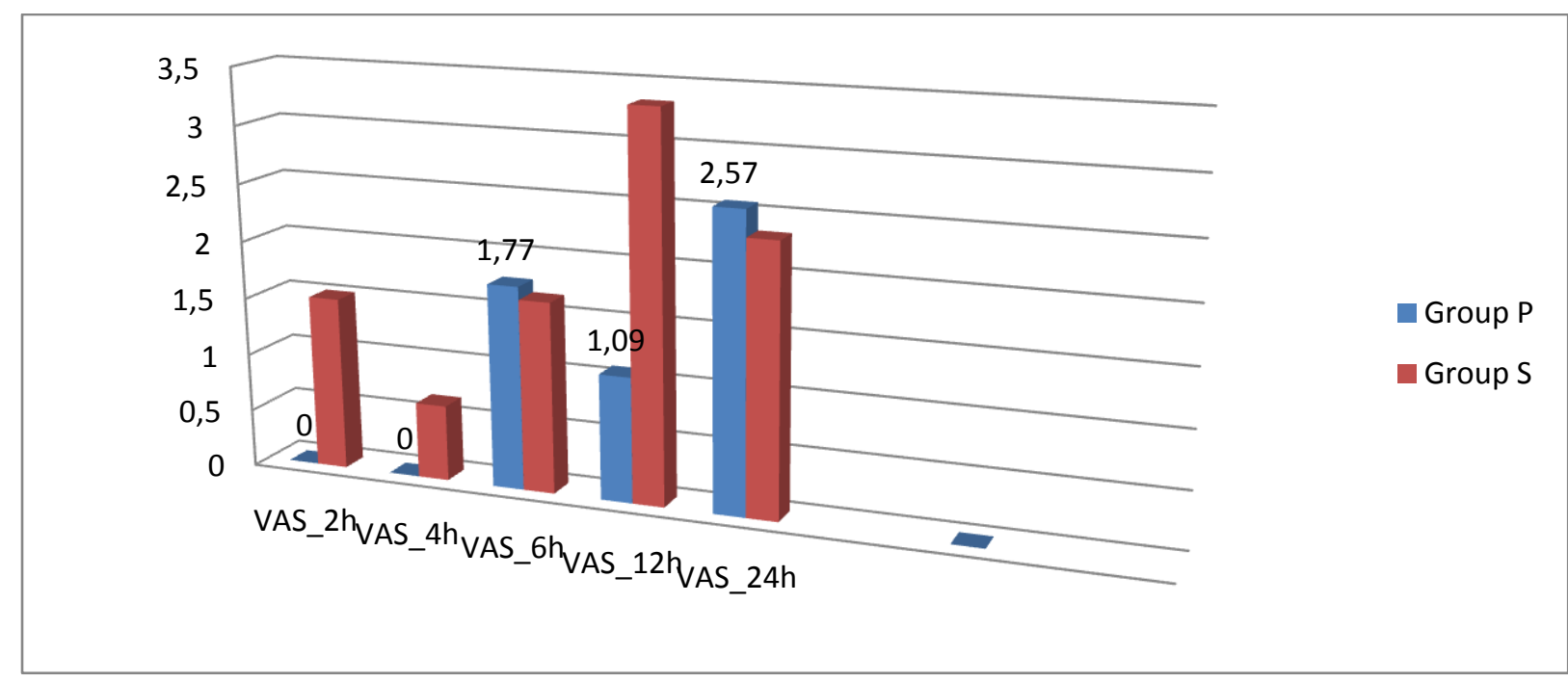

\section{Modified Aldrete score (MAS)}

The patients of group $\mathrm{P}$ showed statistically significant increase in MAS score in comparison to the patients of group $S$ at $2^{\text {nd }}$ hour.

Figure 11: Trend of MAS in both groups

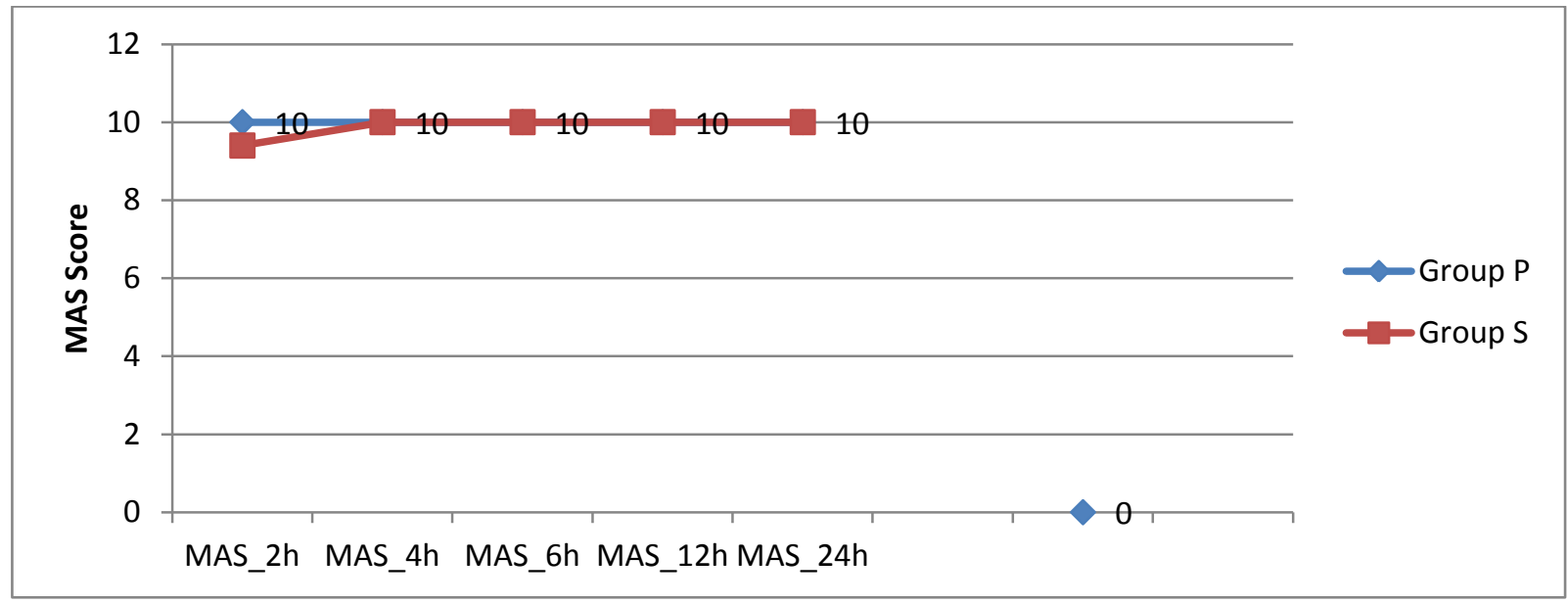

Incidence side effects like PONV, shivering, urinary retention were slightly higher in group $\mathrm{S}$, whereas incidence of bloody puncture was slightly higher in Group $\mathrm{P}$, though they were not statistically significant. There was no incidence of pneumothorax or LAST.

\section{Discussion}

The inguinal hernia repair is one of the most common operative procedures performed. Though the laparoscopic repair is increasingly being done, however open repair is still commonest option. The aim remains an ambulatory hernia repair with minimal side effects, better post operative analgesia and a shorter hospital stay ${ }^{9}$.
In spite of various side effects like post-spinal headache, urinary retention, motor blockage of lower limbs, intraoperative hemodynamic variations, delayed mobility and discharge from the hospital, spinal anaesthesia is the most commonly used anaesthesia method ${ }^{10-13}$. The concept of fast-track ambulatory surgery has made it compulsory to use some other regional method of anesthaesia ${ }^{14}$.

Unilateral spinal anaesthesia has been advocated for outpatient procedures, particularly of the foot or knee. This requires maintaining the patient in a lateral position for 5-15 mins to allow concentration of a hyperbaric solution in the dependant leg. This technique allows use of a 
lower dose of drug, but does not appear to provide faster recovery despite reduced pain and nausea in PACU. Its use may be limited to patients at high risk for nausea, and to where the block can be performed in an induction area ${ }^{15}$.

The PVB is a technique of regional anaesthesia which involves the injection of local anaesthetics at multiple levels immediately lateral to the vertebral column into the paravertebral space where the spinal nerves emerge from the intervertebral foraminae and bifurcate into the dorsal and ventral rami ${ }^{16}$. Limitations of PVB are that the technique is time consuming, patient discomfort from multiple injections, chances of pneumothorax and increased risk of inadvertent intravascular injection ${ }^{17}$.

The concept of PVB for inguinal hernia surgeries was proposed by Wassef et.al. ${ }^{18}$ in 1998. They compared PVB with field block. The paravertebral approach showed a significantly higher success rate than field block, regarding frequency of pain relative to surgical manipulation of spermatic cord, hernia sac. It required less local anaesthetic and less needle insertion than the field block. They concluded that paravertebral nerve root block is superior to the field block, devoid of side effects, and acceptable to the patients.

Later Klein et al. ${ }^{19}$ in 2002 compared PVB with peripheral neural block for postoperative analgesia in patients undergoing inguinal herniorrhaphy under general anaesthesia and concluded that PVB provides analgesia equivalent to extensive peripheral nerve block, offering an alternative method of postoperative pain management and perhaps fewer side effects.

Weltz et al. ${ }^{16}$ in 2003 evaluated the efficacy of PVB in inguinal herniorrhaphy as an ambulatory procedure and found that PVB ensured minimal postoperative pain and lower use of narcotics, lower incidence of PONV and shorter hospital stay.

Later these were confirmed by Hadzic et.al. ${ }^{20}$ in 2006 who compared paravertebral anaesthesia with general anaesthesia for inguinal hernia repair. Again Naja et al. ${ }^{21}$ in 2006, compared the efficacy of nerve stimulator guided PVB with ilio-inguinal nerve block in children undergoing inguinal herniorrhaphy and observed better patient satisfaction in PVB group. In a study, Isil et al. ${ }^{7}$ in 2014, also found prolonged analgesia in PVB group than conventional SA.

In the current study the safety and efficacy of PVB has been compared with unilateral SA in inguinal hernia repair in non ambulatory setting.

Intra-operative and post-operative haemodynamic parameters were significantly different in both the groups. During initial phase (5mins) after unilateral spinal block the SBP \& MAP was relatively stable. However later on (15mins to 2hrs) there was significant fall in the same parameters. This may be due to maintenance of lateral position for $1 \mathrm{st} 10 \mathrm{mins}$ in spinal group, which kept the block unilateral only for some time and as the patient was made supine the block spread to the opposite side causing a sharp fall in these parameters. But in group $\mathrm{P}$, immediately after the PVB block there was significant fall in SBP \& MAP which stabilised after 15 mins. This may be attributed to the relatively large amount of LA being deposited in the paraneuraxis resulting in sudden sympathetic block. In group $\mathrm{P}$, lesser hemodynamic derangement may be due to only unilateral segmental sympathetic block (T10-L1) and more anterior placement of sympathetic chain in the paravertebral space leading to lesser sympathetic block. But in group $\mathrm{S}$, autonomic block extends 2-4 segment above the level of injection, leading to greater fall in HR, SBP, DBP, MAP and also the peak level of sensory block was significantly higher in group S (upto T4) than in group P (up to T8).

The duration of analgesia which was assessed by time to administration of $1 \mathrm{st}$ rescue analgesic was significantly longer in group $\mathrm{P}(8.76 \pm 0.511$ hours $)$ in comparison to group $S(3.15 \pm 0.383$ hours $)$ in this study. This is likely due to relative avascularity of paravertebral space leading to slow uptake of local anaesthetic and use of larger amount of drug in PVB than in unilateral SA.

The total rescue analgesic requirement in $24 \mathrm{hrs}$, time to recovery from motor block \& time to ambulation was significantly higher in group $S$. 
Time to recovery from sensory block was significantly higher in group P.

The patients of group $S$ showed statistically significant increase in VAS score from $2 h$ to $4 h \&$ $12 \mathrm{~h}$ of post-block period. Group $\mathrm{P}$ showed significant increase in MBS for the duration from 2h to 4 h. Group P showed statistically significant increase in modified Aldrete score up to 4hours after block performance after which the score was equal in both the groups.

The time taken to perform the block and time to loss of pin-prick sensation were significantly less in group $\mathrm{S}$ and it was found that in group $\mathrm{S}$ block level reaches T10 dermatome significantly earlier than in group P. Block performance time was higher in paravertebral group as it was a less familiar technique, needed greater skill. Multiple injections need to be given at 4 different vertebral levels. As the block was given by nerve stimulator technique instead of anatomical landmarks, additional time was needed to adjust the current in the nerve stimulator after eliciting muscle contraction. The block onset time was also higher in paravertebral group as the drug had to travel a longer distance to reach the neural tissue whereas in spinal anaesthesia the drug was injected directly into the subarachnoid space.

There was no incidence of partial block or failed block requiring conversion to GA. This may be due to use of nerve stimulator guided technique which is more precise than blind 'anatomical landmark' technique and performance of 4 segment block rather than 2 segment block.

Incidence of pneumothorax in paravertebral block is $0.5 \%$ as documented by Lonnqvist et.al. ${ }^{17}$ Chance of developing pneumothorax increases if PVB is given in upper thoracic level. Similar to all the previous studies regarding PVB in inguinal herniorrhaphy there was no incidence of pneumothorax in the present study as the block was given in lower thoracic and lumber vertebral level.

There was no incidence of LAST or inadvertent intravascular injection in any of the groups inspite of multiple injections given in group P. Only the incidence of bloody puncture was slightly higher (1 case) in paravertebral group.

Incidences of PONV, shivering and urinary retention were slightly higher in group $S$ but the results were not statistically significant. There was no incidence of urinary retention after PVB as parasympathetic fibres that innervate urinary bladder are not blocked in this technique.

Small sample size was one of the limitations of this study, so further studies should be undertaken with a larger population size. This study was an open label study as blinding was not possible because of the obvious difference between the two techniques used. Another limitation was that since we were in the initial phase of practicing the PVB technique, we used peripheral nerve stimulatorguided technique because ultrasound facilities were not available. Further studies must be done using USG guided paravertebral technique to avoid multiple needle pricks, reduce the total volume of drug, increase patient satisfaction and reduce incidence of block failure and complications. Relative lack of expertise increased the block performance time in paravertebral group, whereas keeping the patient in lateral position for 10mins after SA delayed the start of surgery. The concept of unilateral SA still remains a mystery. More work needs to be done to find out exact dose of LA \& timing of position change to make SA unilateral. In the institution where the study was carried out inguinal herniorrhaphy is not done on a day care basis. So the observed advantages of paravertebral technique could not be put into practical use. However if PVB is judiciously utilized, it may lead to far better control of pain, better patient satisfaction, lesser hospital stay for the patients and much larger turnover of patients for the hospital.

\section{Conclusion}

Paravertebral block can be recommended as a better and safe alternative anaesthetic technique to unilateral spinal anaesthesia for inguinal hernia repair as it provides unilateral and segmental anesthesia, prolonged postoperative analgesia, early ambulation, stable intraoperative 
haemodynamics, and minimal adverse effects. However, the expertise required to perform, procedure-related time and longer onset of effect are main concerns.

Conflict of Interest: Nothing to Declare.

\section{Source of Funding}

The study was conducted in a govt. hospital and all the study equipment and drugs were provided free.

\section{References}

1. Baskerville PA, Jarret PEM. Day case inguinal hernia. Ann $R$ Coll Surg Engl.1983;65:224-5.

2. Young DV. Comparison of local, spinal and general anaesthesia for inguinal hernia repair. Am J Surg.1987;153:560-3.

3. G.J. Wood, J.W. Lloyd, R.E.S. Bullingham, B.J. Britton, D.R.A. Finch. Postoperative analgesia for day-case herniorrhaphy patients. Anaesthesia.1981; 36: 603-610.

4. Oosterlee J, Dudley Haf.Surgery in outpatients. British Medical Journal. 1979; 2: $1459-60$.

5. Cwik J. Postoperative considerations of neuraxial anesthesia. Anesthesiol Clin. 2012;30:433-43.

6. Aklaya F. Postoperative complications and nausea vomiting. Turkiye Klinikleri $J$ Anest Reanim-Special Topics.2008; 1:1126.

7. Isil CT, Cinar ASO, Oba S, Isil RG. Comparison of spinal anaesthesia and paravertebral block in unilateral inguinal hernia repair. Turk J Anaesthesiol Reanim. 2014; 42: 257-263.

8. Sinha SK, Brahmchari Y, Kaur M, Jain A.The comparative evaluation of safety and efficacy of unilateral paravertebral block with conventional spinal anesthesia for inguinal hernia repair. Indian J Anaesth. 2016; 60: 499-505.

9. Mishra M, Mishra SP, Singh SP.
Comparison of spinal with paravertebral block for elective open inguinal hernia repair. World J Med Res. 2016;5:1-6.

10. Ozgun H, Kurt MN, Kurt I, Cevikel MH. Comparison of local, spinal and general anesthesia for inguinal herniorrhaphy. Eur J Surg. 2002;168:455-9.

11. Yilmazlar A, Bilgel H, Donmez C, Guney A, Yilmazlat T, Tokat O. Comparison of ilioinguinal-iliohypogastric nerve block versus spinal anesthesia for inguinal herniorrhaphy. South Med J. 2006; 99:4851.

12. Gupta A, Axelsson K, Thörn SE, Matthiessen P, Larsson LG, Holmström B et al. Low dose bupivacaine plus fentanyl for spinal anesthesia during ambulatory inguinal herniorrhaphy: a comparison between $6 \mathrm{mg}$ and $7.5 \mathrm{mg}$ of bupivacaine. Acta Anaesthesiol Scand. 2003;47:13-9.

13. Kehlet H, Dahl JB. Spinal anesthesia for inguinal hernia repair? Acta Anaesthesiol Scand. 2003; 47:1-2.

14. Salinas FV, Liu SS. Spinal anesthesia: Local anesthetics and adjuncts in the ambulatory setting. Clin Anaesthesiol. 2001; 16:195-210.

15. Mulroy MF: Ambulatory surgery. A practical approach to regional anaesthesia 4th ed. Mulroy MF, Bernards CM, McDonald SB, Salians FV. Lippincott Williams \& Wilkins, a Wolters Kluwer. 2009; 311.

16. Weltz CR, Klein SM, Arbo JE, Greengrass RA. Paravertebral block anesthesia for inguinal hernia repair. World J Surg. 2003; 27: 425-9.

17. Lonnqvist P.A. Paravertebral blockade: Failure rate and complications. Anaesthesia. 1995; 50: 813-15

18. Wassef M.R, Randazzo T, Ward W. The paravertebral nerve root block for inguinal herniorraphy-a comparison with the field block approach. Reg Anesth Pain Med. 1998; 23(5):451-6

19. Klein S, Pietrobon R, Nielsen K. 
Paravertebral somatic nerve block compared with peripheral nerve block for outpatient inguinal herniorrhaphy. Reg Anesth Pain Med. 2002; 27: 476-80

20. Hadzic A, Kerimoglu B, Loreio D, Karaca PE, Claudio RE, Yufa $M$, et al. Paravertebral blocks provide superior same-day recovery over general anesthesia for patients undergoing inguinal hernia repair. Anesth Analg. 2006; 102: 1076-81.

21. Naja ZM, Raf M, Rajab M, Daoud N, Ziade FM, Tannir MA, Lonnqvist PA. A comparison of nerve stimulator guided paravertebral block and ilio-inguinal nerve block for analgesia after inguinal herniorrhaphy in children. Anaesth. 2006; 61: 1064-1068. 